Technical Notes

\title{
Deformation and Strength Characteristics of Simulated Columnar Jointed Rock Mass under Conventional Triaxial Compression Tests
}

\author{
Zhi Song ${ }^{1,2 *}$, Weimin Xiao ${ }^{2}$ \\ ${ }^{1}$ Chengdu Institute of Geology and Mineral Resources, Chengdu, Sichuan, China, 6100811 \\ ${ }^{2}$ Southwest Jiaotong University, Chengdu, Sichuan, China 610031
}

\begin{abstract}
The columnar jointed rock mass is a type of extrusive igneous rock. Correctly understanding the deformation and strength characteristics of columnar jointed rock mass under triaxial stress condition is essential for hydropower station and underground cavern excavation. As it is difficult to obtain the mechanical properties of columnar jointed rock mass by field tests, conventional triaxial compression tests were carried out on simulated columnar jointed rock mass specimens with different dip angles between the direction of principal stress and the column prisms. The changes of Young's modulus and peak compressive strength with dip angle $\beta$ were obtained. The results indicate that the Young's modulus and peak compressive strength increase with confining pressure for the same group of specimens. However, under the same confining pressure, the curves of Young's modulus and peak strength versus dip angle resemble a "decreasing-order shape", that is, the Young's modulus and peak strength decrease with dip angle $\beta$ from $0^{\circ}$ to $45^{\circ}$, reach minimum values at $\beta=45^{\circ}$, and then remain relatively constant with the increase of dip angle. Furthermore, four typical failure modes of columnar jointed rock mass specimens under triaxial compression condition are summarized based on the test results. Their failure mechanisms are also discussed.
\end{abstract}

Keywords : rock mechanics, columnar jointed rock mass, deformation and strength, conventional triaxial compression test

\section{Introduction}

Understanding rock mass deformation and its strength characteristics is critical in rock engineering and design of large underground structures in rock masses. This is one of the most important subjects in rock mechanics and rock engineering. Columnar jointed rock mass, as a special structural rock mass, is characterized by anisotropy, discontinuity and non-homogeneity (Zheng et al 2007). Columnar jointed rock mass dominated by basalt is widely distributed across the southwestern region of China (Zhang et al 1999). With the development of transportation infrastructure and hydropower constructions in this area, more and more extra-large rock mass projects are designed and built based on the consideration of the columnar jointed rock mass. Examples include the Xiluodu Hydropower Station and Baihetan Hydropower Station at the downstream of Jinsha River, Longkaikou Hydropower Station at the middle stream and associated extra-long traffic tunnels. These columnar jointed rock masses are generally in a triaxial stress state. Therefore, research on the deformation and strength characteristics of columnar jointed rock mass in a triaxial stress state is important to understanding failure mode of columnar jointed rock mass as well as to the stability control of the rock masses.

* Corresponding Author: Corresponding author: Song Zhi, songzhi2015@126.com, Tel: +86 139 8076-319

Copyright (C Canamaple Academia Services, http://press.camdemia.ca

DOI: 10.15273 /ijge.2016.02.009 
The conventional triaxial test, as a very important approach for analyzing the mechanical properties of materials under the triaxial state of stress, has been widely used in study of rock deformation and strength characteristics (Cheng and Shen 1987, Zhou et al 2005, Yang et al 2008, Yin et al 2009, Zhang et al 2011). Jointed rock masses are cut by joint fissures of various scales, which are structurally complex and fragile, and sample making is very difficult. Natural columnar jointed rock masses are generally shaped as pentagon or hexagon with columns of two or three groups of columnar jointed rock masses. As the column rock mass is large in the field, it is very difficult to cut a small sized sample which contains columnar jointed structure suitable for triaxial test. Large scale tests carried out in-situ are time consuming and expensive. Moreover, being affected by the filed surroundings and restricted by the existing technology of in-situ tests, such test results are often not representative of the real condition (Zhu et al 2009). Rock-like materials with simulated rock structures are easy to use and efficient. The method for analyzing the mechanical characteristics of rock masses by stimulation has been widely applied (Tien and Tsao 2000, Tien and Kuo 2001, Tien et al 2006, Deng and $\mathrm{Fu}$ 2011). Some scholars have also attempted to use this method for making the rock structural model in uniaxial or biaxial test (Brown 1970, Einstein and Hirschfeld 1973, Kultilake et al 1997). However, results of triaxial test for mechanical characteristics of columnar jointed rock masses are seldom reported or published because standard jointed rock specimens are difficult to fabricate. Xiao et al (2014) used gypsum mixture to make hexagonal prisms, where cement slurry was used to bond into a simulated columnar rock masses. They overcame the difficulties in sample preparation, and uniaxial compression tests were conducted to study the deformation and strength anisotropy of simulated columnar jointed rock mass, and meaningful results were obtained.

This paper describes preparation of cylindrical simulated columnar jointed rock mass specimens, analyzes the deformation and strength characteristics of simulated columnar jointed rock mass under different confining pressures through the conventional triaxial test, and further explores their typical failure modes and strength characteristics.

\section{Test Overview}

\subsection{Specimen preparation}

The model material is a mixture comprising gypsum, ordinary Portland cement and water in a weight ratio of $3: 1: 3.2$. To restrict bubbles generated during the hydration of gypsum, defoaming agent was added into the mixture of gypsum and cement at a weight ratio of $0.2 \%$ of the mixture. Physical and mechanical properties of model materials are shown in Table 1 .

Table 1 Physical and mechanical properties of model material

\begin{tabular}{lcll}
\hline \multicolumn{1}{c}{ Parameter } & Value & \multicolumn{1}{c}{ Parameter } & Value \\
\hline Density $\rho\left(\mathrm{g} / \mathrm{cm}^{3}\right)$ & 1.052 & Modulus of Elasticity $E_{i}(\mathrm{MPa})$ & 347.0 \\
\hline Poisson's ratio & 0.1 & $\begin{array}{l}\text { Uniaxial compressive strength } \\
\sigma_{c i}(\mathrm{MPa})\end{array}$ & 2.638 \\
\hline Cohesion $c(\mathrm{MPa})$ & 0.173 & Tensile strength $\sigma_{t}(\mathrm{MPa})$ & 0.584 \\
\hline Internal friction angle $\varphi\left(^{\circ}\right)$ & 18.9 & & \\
\hline
\end{tabular}

Regular hexagonal prisms were used to simulate single cylinder in the columnar jointed rock masses. The column length is about $40 \mathrm{~cm}$ and side length is $1 \mathrm{~cm}$. Individual columns were bonded into a columnar jointed rock model using cement slurry in a cement-to-water weight ratio of $3: 2$, then were cut and trimmed into $\varphi 50 \mathrm{~mm} \times$ H $100 \mathrm{~mm}$ standard cylindrical specimens with different angles $(\beta)$ between the column and the prism. $\beta$ is $0^{\circ}, 15^{\circ}, 30^{\circ}, 45^{\circ}, 60^{\circ}, 75^{\circ}$ and $90^{\circ}$, respectively, accounting to 7 groups of columnar jointed rock mass specimens in total (Fig. 1). 


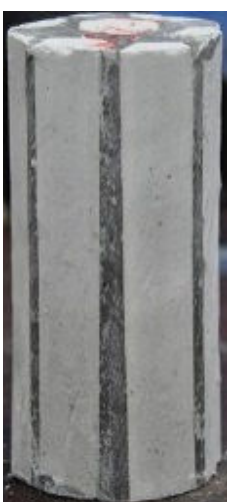

(a) $\beta=0^{\circ}$

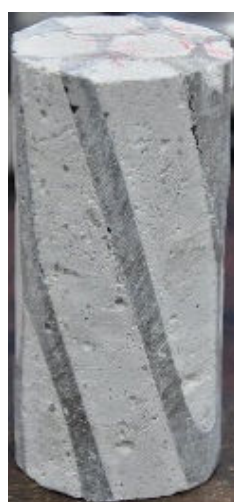

(b) $\beta=15^{\circ}$

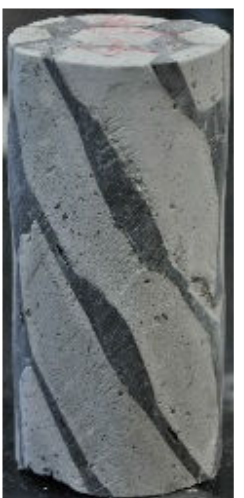

(c) $\beta=30^{\circ}$

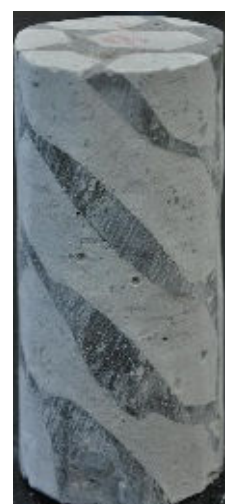

(d) $\beta=45^{\circ}$

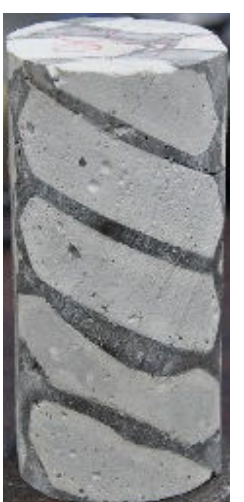

(e) $\beta=60^{\circ}$

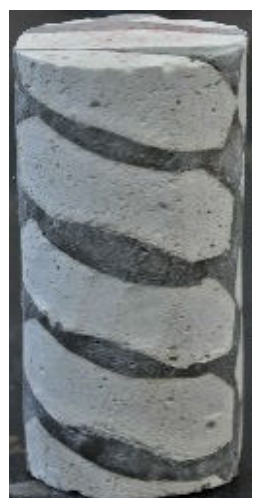

(f) $\beta=75^{\circ}$

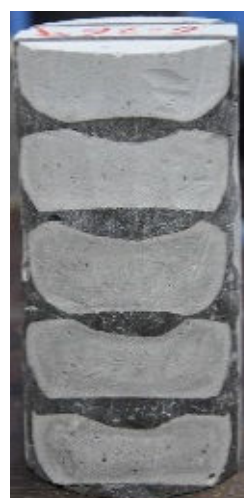

(g) $\beta=90^{\circ}$

Fig. 1 Cylindrical columnar jointed rock mass specimens

\subsection{Test plan}

Conventional triaxial compressive test on columnar jointed rock mass specimens was conducted using the MTS815 rock mechanics testing system (Fig. 2a) in the National Key Laboratory of Geologic Hazard Prevention and Geologic Environmental Protection at Chengdu University of Technology. The axial and circumference deformations in specimens were measured with a displacement sensor. The circumference deformation was measured using a chain circumferential extensometer (Fig. 2b).

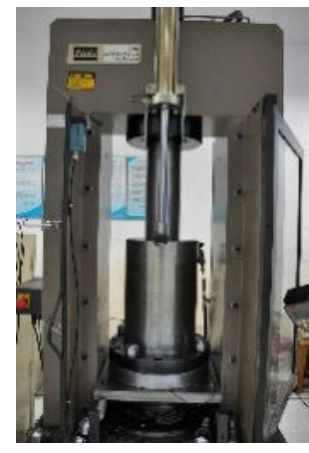

(a) Test system

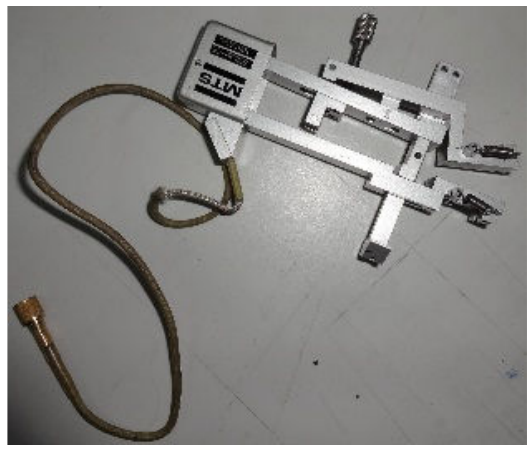

(b) Circumferential extensometer
Fig. 2 MTS-815 rock mechanics testing system

The confining pressure stresses in the conventional triaxial test can be divided into five levels according to model materials' compressive strength, i.e. 0.0 $\mathrm{MPa}, 1.6 \mathrm{MPa}, 2.4 \mathrm{MPa}, 3.2$ $\mathrm{MPa}$ and 4.0 $\mathrm{MPa}$. Confining pressure on specimens was imposed manually, and axial load was imposed when the confining pressure reached to a pre-set value. Axial loading was supported by displacement control with a loading rate of $0.2 \mathrm{~mm} / \mathrm{min}$.

\section{Test Results}

\subsection{Deformation characteristics}

The typical stress-strain curves of the seven group specimens at the five levels' confining pressures under the conventional triaxial compression are shown in Fig. 3. The stress-strain curves can be grouped into three types based on change patterns:

Class I - the stress-strain curve increases almost linearly before reaching the peak value, and then quickly drops to the residual stage, which indicates the strain-softening property. This pattern happens when specimen angle is $0^{\circ}$ (Fig 3a).

Class II - The front section before peak value is flatter than that of Class I but still displays an increase trend. After reaching the peak value, the curve gradually transitions to the residual stage, which is characterized by nearly perfect plasticity. This pattern applies to $\beta=15^{\circ}, 30^{\circ}$ and $45^{\circ}$, as shown in Figs. 3b, 3c and $3 d$.

Class III - The front section before peak increases steeply with the increase of confining pressure. After reaching the peak value, the curve increases linearly but in a slow speed. However, there is no an obvious residual stage, and the strain-hardening property is obvious. This pattern refers to Figs. 3e, $3 \mathrm{f}$ and $3 \mathrm{~g}$ for the specimen angle $\beta=60^{\circ}, 75^{\circ}$ and $90^{\circ}$. 

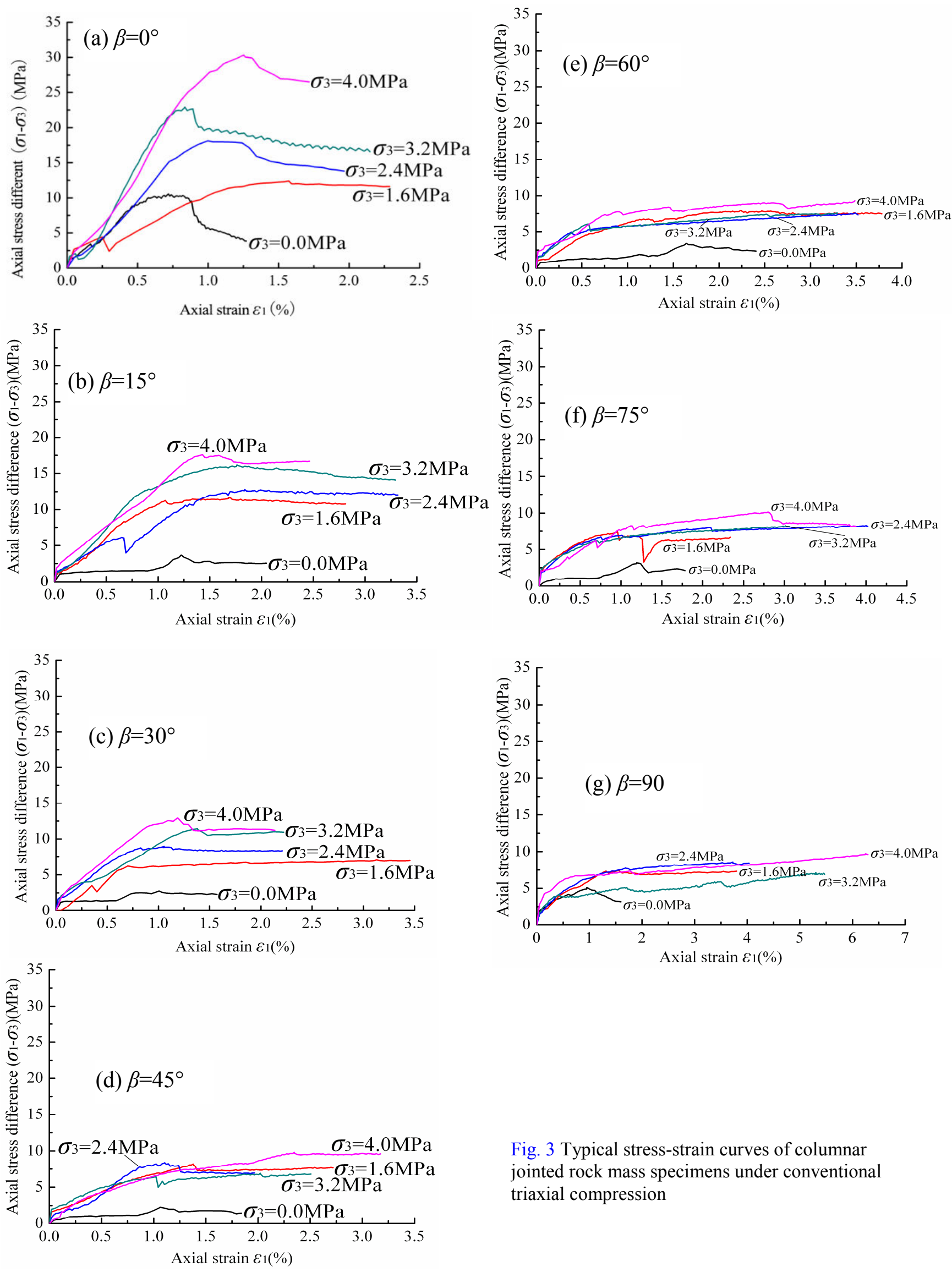

Fig. 3 Typical stress-strain curves of columnar jointed rock mass specimens under conventional triaxial compression 
Table 2 Young's modulus and peak strength of columnar jointed rock mass specimens under different confining pressures

\begin{tabular}{cccccccccccccccccc}
\hline $\begin{array}{c}\text { Confining } \\
\text { pressure } \\
\text { level } \\
(\mathrm{MPa})\end{array}$ & \multicolumn{2}{c}{$\beta=0^{\circ}$} & \multicolumn{2}{c}{$\beta=15^{\circ}$} & \multicolumn{2}{c}{$\beta=30^{\circ}$} & \multicolumn{2}{c}{$\beta=45^{\circ}$} & $\beta=60^{\circ}$ & \multicolumn{3}{c}{$\beta=75^{\circ}$} & \multicolumn{3}{c}{$\beta=90^{\circ}$} & \multicolumn{2}{c}{$\begin{array}{c}\text { Aeolotropy } \\
\text { ratio }\end{array}$} \\
\hline & $E_{r}$ & $\Delta \sigma_{p}$ & $E_{r}$ & $\Delta \sigma_{p}$ & $E_{r}$ & $\Delta \sigma_{p}$ & $E_{r}$ & $\Delta \sigma_{p}$ & $E_{r}$ & $\Delta \sigma_{p}$ & $E_{r}$ & $\Delta \sigma_{p}$ & $E_{r}$ & $\Delta \sigma_{p}$ & $E_{r}$ & $\Delta \sigma_{p}$ \\
\hline 0.0 & 1716 & 10.6 & 660 & 3.7 & 664 & 2.8 & 517 & 2.3 & 514 & 3.4 & 456 & 3.2 & 403 & 5.1 & 4.3 & 4.6 \\
\hline 1.6 & 1581 & 12.4 & 1080 & 11.6 & 1020 & 7.1 & 534 & 8.2 & 540 & 8.0 & 658 & 7.5 & 461 & 7.5 & 3.4 & 1.7 \\
\hline 2.4 & 2028 & 18.1 & 707 & 12.8 & 954 & 9.0 & 857 & 8.3 & 932 & 7.5 & 701 & 8.3 & 497 & 8.6 & 4.1 & 2.4 \\
\hline 3.2 & 3152 & 22.9 & 1397 & 16.2 & 757 & 11.5 & 506 & 6.9 & 839 & 7.6 & 541 & 8.2 & 708 & 7.1 & 6.2 & 3.3 \\
\hline 4.0 & 2704 & 30.3 & 1155 & 17.6 & 1085 & 12.9 & 521 & 9.8 & 676 & 9.3 & 678 & 10.2 & 421 & 9.7 & 6.4 & 3.3 \\
\hline
\end{tabular}

The peak strength $\Delta \sigma_{p}$ is determined based on the stress-strain curve, and the modulus of elasticity $E_{r}$ based on the methods prescribed in Chinses Standard Tests methods of rock for highway engineering (JTG E41-2005). Table 2 shows the trend of $E_{r}$ changing with angle $\beta$ under the five levels confining pressure stresses. According to the test results, the modulus of elasticity of columnar jointed rock mass specimens becomes greater when confining pressure increases, and this trend is not dependent on $\beta$. Under the same level of confining pressure, the modulus of elasticity becomes smaller with an increased $\beta$ and reaches the minimum value when $\beta$ equals $45^{\circ}$. After that, the modulus of elasticity remains stable as the angle $\beta$ increases.

\subsection{Strength characteristics}

The peak strength $\Delta \sigma_{p}$ of a columnar jointed rock mass specimen under the conventional triaxial compression is equal to the axial stress difference $\left(\sigma_{1}-\sigma_{3}\right)_{p}$ when the specimen is failed. According to the test (Table 2), we can calculate the changes of peak strength in columnar jointed rock mass specimens with a given angle $\beta$ under different confining pressure levels, as shown in Fig. 4. The results show that under all confining pressure levels, the peak strength of a specimen will reach the maximum value when $\beta$ equals 0 , because the column is impossible to slide along the jointed surface under the forces of axial pressure and confining pressure. The specimens' peak strength can be grouped into two types depending on their change curves along dip angle under different confining pressure levels: the first one is that, when the confining pressure $\sigma_{3}$ equals $0.0 \mathrm{MPa}$, the peak strength $\Delta \sigma_{p}$ presents an "U" shape (flat on bottom and slightly rising on both shoulders), i.e. $\Delta \sigma_{p}$ decreases gradually when $\beta$ increases from $0^{\circ}$ to $30^{\circ}$, and reaches the minimum value when $\beta$ is between $30^{\circ}$ and $60^{\circ}$. After that, $\Delta \sigma_{p}$ slowly increases when the angle $\beta$ gets greater, but the peak strength at $\beta=90^{\circ}$ is smaller than that at $0^{\circ}$; the second type that $\Delta \sigma_{p}$ decreases from the maximum value when $\beta$ equals $0^{\circ}$ all through to the minimum value when $\beta$ equals $45^{\circ}$, after which $\Delta \sigma_{p}$ will not change greatly with dip angle increases and remains relatively constant.

Moreover, stress-strain curves shown in Fig. 3 reveal that the residual strength $\Delta \sigma_{\text {res }}$ in columnar jointed rock mass specimens under conventional triaxial compression vary along with $\beta$. The ratio of residual strength $\Delta \sigma_{\text {res }}$ to corresponding peak strength $\Delta \sigma_{p}\left(\Delta \sigma_{r e s} / \Delta \sigma_{p}\right)$ indicates the dropping magnitude in the post-peak strength of the specimens (Fig. 5). When $\beta$ is $0^{\circ}$, the post-peak residual strength will decline to $74.3 \%$ of the peak value. Within the range of $\beta=15^{\circ} \sim 45^{\circ}$, the post-peak strength will drop by about $7 \% \sim 8 \%$. With further increase of the angle to $60^{\circ}$ till $90^{\circ}$, the post-peak strength will slightly drop within a range of $4 \%$.

\subsection{Characteristics of specimen failure}

The typical failure modes of the specimens at different dip angles can be divided into four types: (1) axial splitting failure along model material, where cracks are mostly developed along axial direction in the model material, and the cracks make the specimen expand. However, restricted by the lateral confining pressure, the lateral expansion of the specimen is not so obvious as that under the uniaxial compression conditions;

(2) a single, flat and straight main shear face is 


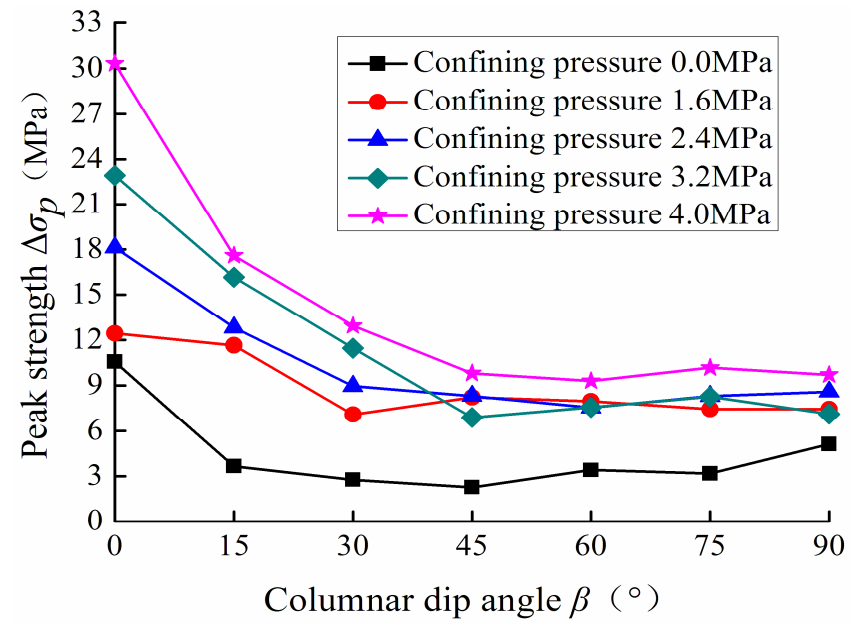

Fig. 4 Changes of peak strength in columnar jointed rock mass specimens along dip angle $\beta$ under different confining pressures

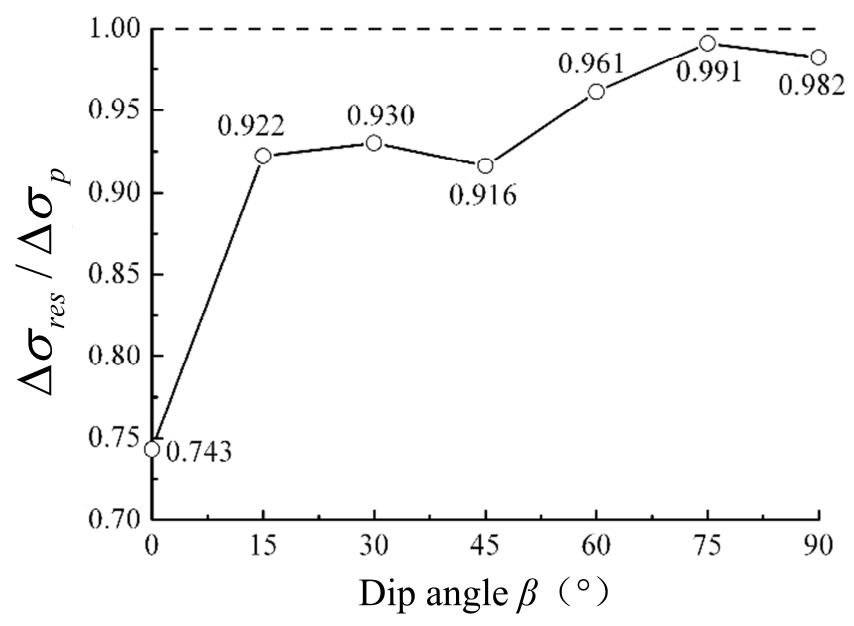

Fig. 5 Changes of $\Delta \sigma r e s / \Delta \sigma p$ with dip angle $\beta$

formed along model material in a direction roughly parallel to the column. This is mainly because the local strain changes occur inside the model material, which further forms the main shear flat surface; (3) the composite failed surface partly passes through model material, and partly passes along the columnar jointed surface; (4) the failed surface is a "Y" shape conjugated shear surface. This is mainly because the confining pressure provides a lateral restraint, which hinders the failures along the jointed surface as well as the axial splitting failure.

\section{Result Analysis and Discussion}

According to this test, the deformation and strength characteristics of the columnar jointed rock mass specimens under triaxial compression are largely different from those under uniaxial compression:

Firstly, as $\beta$ changes from $0^{\circ}$ to $90^{\circ}$, the modulus of elasticity $E_{r}$ and the peak strength in the specimens under the triaxial compression changes from an obvious " $U$ " shape curve to a descending curve, in which $E_{r}$ and the peak strength reach the minimum value when $\beta=45^{\circ}$. Therefore, the changing trends of $E_{r}$ and $\Delta \sigma_{p}$ can be described by functions divided by sections: when $\beta=0^{\circ} \sim 45^{\circ}$, the changing curve of $E_{r}$ and $\Delta \sigma_{p}$ with the changing angle follows the empirical formula proposed by Ramamurthy (1993); and when $\beta=45^{\circ} \sim 90^{\circ}$, the changing curves of $E_{r}$ and $\Delta \sigma_{p}$ with dip angle can be described by the negative exponential function.

Then, the aeolotropy ratio of modulus of elasticity and peak strength of the columnar jointed rock mass under the triaxial compression is calculated based on $E_{r \max } / E_{r \min }$ and $\Delta \sigma_{\text {pmax }} / \Delta \sigma_{\text {pmin }}$ proposed by Ramamurthy and Arora (1994), as shown in the last two columns of Table 2. The aeolotropy classification criteria given by Ramamurthy (1993) can be referenced to infer that the modulus of elasticity and peak strength of the columnar jointed rock mass under the triaxial compression is presented by the moderate aeolotropy. However, the precondition of the Ramamurthy's formula is that the changing curve of modulus of elasticity and peak strength along angle is in "U" shape. Since the two changing curves in our study is descending when $\beta$ smaller than $45^{\circ}$ and remains stable when $\beta$ is between $45^{\circ} \sim 90^{\circ}$, it indicates that the aeolotropy degree may be overestimated by Ramamurthy (1993). Therefore, we recommend to degrade the aeolotropy of the modulus of elasticity and peak strength of the columnar jointed rock mass under the triaxial compression to a lower aeolotropy level.

Finally, except that $\beta$ equals $0^{\circ}$, the typical failure modes of the specimens under triaxial compression change greatly. When the angle is small $\left(\beta=15^{\circ} \sim 30^{\circ}\right)$, as the confining pressure is high, which restricts specimens' lateral deformation, and the shear strength on columnar jointed surface increases, the model material is yielded to form a shear surface in the direction 
parallel to the column. In case of a moderate angle $\left(\beta=45^{\circ} \sim 75^{\circ}\right)$, the model material and the columnar jointed surface jointly bear the axial load. At the specimen failure stage, the model material and columnar jointed surface are shielded successively to form a composite failure surface. In case of a high angle $\left(\beta=90^{\circ}\right)$, it is the model material that primarily bears the load while the jointed surface will not react. It is similar to that when $\beta$ is $0^{\circ}$, in which the model material will be yielded as the specimen fails. However, the restraints of the confining pressure prevent the axial tension, therefore failure of the specimen, and the shear failure will occur inside the model material and a macro conjugated shear failure surface can be eventually formed.

Therefore, under the triaxial compression, the confining pressure has significant impact on the deformation and strength characteristics as well as failure modes in the columnar jointed rock mass specimens. We must use 3D stress conditions to study the constitutive model and failure features, which is the key to subsequent theoretical research.

Moreover, in order to ensure the integrity of the columnar jointed rock mass specimens before cutting and sampling, cement slurry is used fabricating the columnar jointed rock mass model. Because of the irregular shapes of individual columns, cement slurry cement is formed in a certain cementation thickness, which may affect the test results, specifically when specimen curing duration passes seven days or longer. The cementation layer of cement mortar has certain strength and can bear some loads. As shown in Table 2, when the confining pressure is $0.0 \mathrm{MPa}$, the peak strength of most specimens exceeds the uniaxial compressive strength of the gypsum model material. This is the defect of this study.

\section{Conclusions}

Conventional triaxial compression tests were carried out on the simulated columnar jointed rock mass specimens with different dip angles. The deformation and strength characteristics of the specimens under triaxial compression conditions are studied. Main conclusions include:
(1) The stress-strain curve of the columnar jointed rock mass specimens under triaxial compression can be divided into three groups depending on dip angles: first, strain softening curve at $\beta$ of $0^{\circ}$; second, elastic curve, corresponding to the specimen angle $\beta$ of $15^{\circ}, 30^{\circ}$ and $45^{\circ}$; and third, strain hardening curve, corresponding to the specimen angle $\beta$ of $60^{\circ}, 75^{\circ}$ and $90^{\circ}$.

(2) Due to the impact of the confining pressure, the variation of modulus of elasticity $E_{r}$ and peak strength $\Delta \sigma_{p}$ of columnar jointed rock mass specimens along dip angle is not in an "U" shape, but a descending curve. In other words, $E_{r}$ and $\Delta \sigma_{p}$ begin to reduce as $\beta$ increases from $0^{\circ}$, and will not rise again when they reach the minimum values at $\beta$ of $45^{\circ}$, but remain at that level instead.

(3) There are four typical failure modes of columnar jointed rock mass specimens under triaxial compression: (1) the axial splitting failure along the model material; (2) a single, flat and straight main shear face is formed along the model material in the direction roughly parallel to the columns; (3) the composite failed surface partly passes through model material, and partly passes along the columnar jointed surface; (4) "Y" shaped conjugated shear surface passing through the model material.

\section{References}

Brown, E.T., 1970. Strength of models of rock with intermittent joints. Journal of Soil Mechanics and Foundations Division, 96(6): 1935 - 1949.

Cheng, H.X. and M.R. Shen, 1987. Triaxial test of a single block on a common liquid press. Chinese Journal of Rock Mechanics and Engineering, 6(1): 39 - 46.

Deng, R. and X. Fu. 2011. On the simulative experimental study of mechanical properties of stratified rock mass. Journal of Experimental Mechanics, 26(6): 721 - 729.

Einstein, H.H. and R.C. Hirschfeld, 1973. Model studies in mechanics of jointed rocks. Journal of Soil Mechanics and Foundations Division, 99(3): 229 - 248. 
Kultilake, P.H.S.W., W. He, J. Um and H. Wang, 1997. A physical model study of jointed rock masses strength under uniaxial compressive loading. International Journal of Rock Mechanics and Mining Sciences, 34(3-4), paper No.165.

Ramamurthy, T. 1993. Strength and modulus responses of anisotropic rocks. In: Comprehensive Rock Engineering Vol.1. Brown, E.T. (eds), Pergamon Press, Oxford, pp: 313 - 329.

Ramamurthy, T. and V.K. Arora, 1994. Strength predictions for jointed rocks in confined and unconfined states. International Journal of Rock Mechanics and Mining Sciences \& Geomechanics, Abstracts, 31(1): 9 - 22.

Test methods of rock for highway Engineering(JTG E41-2005). Beijing: China Communication Press.

Tien, Y.M. and M.C. Kuo Mingchuan, 2001. A failure criterion for transversely isotropic rocks. International Journal of Rock Mechanics and Mining Sciences, 38(3): 399 412.

Tien, Y.M., M.C. Kuo and C. Juang, 2006. An experimental Investigation of the failure mechanism of simulated transversely isotropic rocks. International Journal of Rock Mechanics and Mining Sciences, 43(8): 1163 1181.

Tien, Y.M. and P. Tsao, 2000. Preparation and mechanical properties of artificial transversely isotropic rock. International Journal of Rock Mechanics and Mining Sciences, 37(6): 1001 -1012 .

Xiao, W.M., R.G. Deng, X.M. Fu, C.Y. Wang. 2014. Model studies on deformation and strength anisotropy of columnar jointed rock masses under uniaxial compression condition. Chinese Journal of Rock Mechanics and Engineering, 33(5): 2817 - 2826.
Yang, G.L., R.Q. Huang, G.J. Cai, X.M. Fu, F. Lin, D.M. Xu. 2008. Conventional triaxial compression test of altered rock: study of classification of strain-stresss curve before and after destruction and brittle-ductile diversion confining pressure. Rock and Soil Mechanics, 29(10): 2759 - 2763.

Yin, G.Z., X.S. Li and H.B. Zhao, 2009. Experimental investigation on mechanical properties of coarse sandstone after high temperature under conventional triaxial compression. Chinese Journal of Rock Mechanics and Engineering, 28(3): 598 - 604.

Zhang, Q., Q. Qian, Y. Wang, P. Xu, S. Han, X.Q. Jia. 1999. Late paleozoic basic magmatism from SW Yangtze massif and evolution of the Paleo-Tethyan Ocean. Acta Petrologica Sinica, 15(4): 576 - 583.

Zhang, Z.L., W.Y. Xu, W. Wang, R.B. Wang. 2011. Investigation on conventional triaxial compression tests of ductile rock and law of deformtion and damage evolution. Chinese Journal of Rock Mechanics and Engineering, 30(Supp.2): 3857 - 3862.

Zheng, W.T., W.Y. Xu, A.Q. Wu, H.M Zhou, G.Y. Wu, C.A. Shi. 2007. Numerical in-situ testing of excavation experimental cavity on columnar joints. Rock and Soil Mechanics, 28(supp.): 253 - 257.

Zhou, Y.H., D.P. Zhou and Z.J. Feng. 2005. Strength and deformation of three types of red beds under conventional triaxial compression. Journal of Engineering Geology, 13(4): 477 480.

Zhu, D.J., L.D. Yang and Y.C. Cai, 2009. Simulation of compressive failure process of columnar jointed rock mass and its failure mechanism analysis. Chinese Journal of Rock Mechanics and Engineering, 28(4): 716 - 724. 